\title{
ANÁLISE COMPARATIVA ENTRE OS JORNAIS EL PAÍS E FOLHA DE SÃO PAULONA FINAL DA COPA DAS CONFEDERAÇÕES
}

\author{
COMPARATIVE ANALYSIS OF THE COVERAGE OF THE FINAL MATCH OF THE \\ 2013 CONFEDERATIONS CUP IN THE NEWSPAPERS EL PAÍS (SPAIN) AND \\ FOLHA DE SÃO PAULO (BRAZIL)
}

ANÁLISIS COMPARATIVO ENTRE LOS PERIÓDICOS EL PAÍS Y FOLHA DE S. PAULO DURANTE LA COBERTURA DE LA ETAPA FINAL DE LA COPA DE LAS CONFEDERACIONES

\section{Gustavo Roese Sanfelice*, Joaquin Marin Montin**, Lafaiete Luiz de Oliveira Junior $^{\star \star *}$, Alessandra Fernandes Feltes ${ }^{\star \star \star *}$, Norberto Kuhn Junior ${ }^{\star \star \star \star \star}$}

\section{Palavras-chave}

Mídia. Futebol.

Copa das

Confederações.

Keywords

Media.

Football.

Confederations Cup.

Palabras clave

Medios.

Fútbol.

Copa de las

Confederaciones.
Resumo: 0 objetivo deste trabalho foi identificar e interpretar a produção de sentido estabelecida pelos jornais Folha de S. Paulo (Brasil) e El País (Espanha) sobre a cobertura da final Copa das Confederações no Brasil em 2013. Foram analisados os jornais Folha de S. Paulo e El País de 27 de junho a 2 de julho de 2013. A partir das unidades de significados, chegamos às seguintes categorias: Esporte resultado; Esporte economia; Esporte infraestrutura; Questões políticas e sociais e Publicidade. Concluímos que as manifestações populares se ofertaram como um acontecimento midiático na cobertura dos jornais analisados, possibilitando um protagonismo juntamente com o esporte/ resultado.

Abstract: The aim of this study was to identify and interpret the frames used by the newspapers Folha de São Paulo (Brazil) and El País (Spain) in the coverage of the final match of the Brazil 2013 Confederations Cup. We analyzed reports published in these newspapers from June 27 to July 2, 2013. Through the analysis of these emergent themes, the following categories were identified: sport results, sport economy, sport infrastructure, political and social issues, and advertising. We conclude that the popular protests that occurred during the tournament received substantial media attention that rivaled the coverage devoted to the sport results.

Resumen: El objetivo de este trabajo fue identificar e interpretar el conjunto de significados establecidos por los periódicos Folha de S. Paulo/Brasil y El País/España durante la cobertura de la etapa final de la Copa de las Confederaciones en Brasil, realizada en 2013, a través del análisis de noticias y reportajes publicados en dichos periódicos entre el 27 de junio y el 02 de julio de ese año. A partir de las unidades de significado se llegó a las siguientes categorías: Deporte resultado; Deporte economía; Deporte infraestructura; Cuestiones políticas y sociales y Publicidad. Concluimos que las manifestaciones populares constituyeron un acontecimiento mediático en la cobertura de los diarios analizados, convirtiéndose en protagonistas de las noticias junto a la categoría deporte/ resultado
*Universidade Feevale, Novo Hamburgo, RS, Brasil. E-mail: sanfeliceg@ hotmail.com

** Universidad de Sevilla, Sevilha, Espanha. E-mail: jmontin@us.es

*** Universidade Feevale, Novo Hamburgo, RS, Brasil. E-mail: afaiete_junior@ hotmail.com

**** Universidade Feevale, Novo Hamburgo, RS, Brasil. E-mail: alessandrafeltes@gmail.com

***** Universidade Feevale, Novo Hamburgo, RS, Brasil. E-mail: nkjunior@feevale.br

Recebido em: 02-06-2014 Aprovado em: 01-11-2014 (c) (1) (8) Licence 


\section{INTRODUÇÃO}

Os megaeventos esportivos entraram na agenda da mídia brasileira desde os Jogos Pan-americanos do Rio 2007. Desde então, o Brasil está no circuito internacional de competições, haja vista a Copa do Mundo de Futebol da FIFA em 2014 e os Jogos Olímpicos do Rio em 2016. Tal como aconteceu na Espanha no final do século passado, os grandes eventos esportivos se constituíram como uma ferramenta decisiva para a evolução e o desenvolvimento dos meios de comunicação. Desde o mundial de futebol de 1982 até os Jogos Olímpicos de Barcelona de 1992, aconteceu uma série de competições de diferentes especialidades esportivas (Mundobasket 86, Mundial atletismo Sevilla 1999, etc.) de grande impacto sociomidiático. Tais eventos esportivos permitiram à Espanha não só ter projeção internacional no mundo esportivo, como também influenciaram a transformação de suas estruturas econômicas e sociais.

O campo esportivo, com a predileção dos media, especialmente em época de grandes eventos esportivos como os Jogos Olímpicos e a Copa do Mundo de Futebol, vê-se mais e mais exposto ao grande público através das coberturas esportivas, com isso, suas possibilidades de disseminação são alavancadas (SANFELICE, 2010). Como proposta de estudo, tomamos como ponto de partida a compreensão de que o campo midiático, ao tematizar a Copa das Confederações da FIFA 2013, funda um acontecimento cujo enquadramento antecipa a modelagem do "produto-megaevento", que é a Copa do Mundo de 2014, e oferece um "termômetro" sobre o impacto social desse "produto-evento" específico. Sendo assim, o objetivo deste texto é identificar e interpretar a produção de sentido estabelecida pelos jornais Folha de S. Paulo (Brasil) e El País (Espanha) sobre a pré-cobertura e a cobertura da final da Copa das Confederações no Brasil em 2013. Entendemos a Copa das Confederações como extensão do megaevento Copa de 2014. Dessa forma, propomos estudar um jornal brasileiro, a Folha de S. Paulo e o maior jornal espanhol, El País, visando a identificar os aspectos relativos à Copa das Confederações no Brasil em 2013. O Brasil, como sede de 2014, fica evidenciado nas coberturas por sediar o megaevento Copa do Mundo, já a Espanha é a atual campeã mundial, conhecida no âmbito midiático como "La roja", e vai defender sua supremacia futebolística no Brasil em 2014. A grande repercussão que aconteceu a partir dessa denominação se reflete em função das últimas vitórias internacionais da seleção espanhola. De qualquer forma, o conceito "La roja" converteu-se em imagem de marca e principal chamada publicitária do grupo televisivo Mediaset, que é proprietário dos direitos de transmissão dos jogos oficiais da Espanha nos últimos Mundiais e nos campeonatos europeus.

\section{ESPORTE, MEGAEVENTOS ESPORTIVOS, COPA DO MUNDO, MÍDIA}

Não são apenas veículos, mas também produtores de sentido e, consequentemente, têm papel importante em qualquer contexto sociocultural. A questão que sempre retorna em conversas informais, e até mesmo formais, em função da overdose futebolística via mídias, é se o futebol é muito popular porque é muito veiculado, ou se é muito veiculado porque é muito popular. Poucas atividades têm tanta atenção como um grande evento futebolístico. No Brasil, desde os tempos da Colônia, existiam colégios jesuítas, e foi provavelmente através deles que chegaram as primeiras bolas de futebol e se realizaram os primeiros jogos. Ainda não havia clubes, campeonatos e entidades, mas o esporte praticado já era o futebol moderno segundo o modelo inglês. (MELO, 2000). A facilidade de sua prática propiciou uma massificação, possi- 
bilitando ao Brasil revelar vários atletas. A partir de então, o Brasil tem exportado uma grande quantidade de jogadores para as principais equipes do mundo.

Os megaeventos esportivos são grandes eventos que envolvem ao seu redor um conjunto de pessoas e fatores, movimentando países, governos e suas economias, estimulando a população em geral (TAFFAREL; SANTOS JUNIOR; SILVA, 2013). Os megaeventos são caros, por isso é imprescindível planejar os recursos necessários. Na maioria das vezes são deficitários e acabam sendo custeados pelas instituições públicas (AÑó, 2000). Esse fenômeno se caracteriza como um dos acontecimentos mais significativos, relevantes e complexos da sociedade contemporânea. $O$ esporte representa um dos meios de maior mobilização coletiva criado pelos seres humanos, sendo considerado uma área fundamental para a sociedade contemporânea (DUNNING, 2003). Seu destaque resulta, em grande parte, da cobertura midiática, "por sua capacidade de construir sentidos e significados no interior de cada cultura" (MEZZAROBA; PIRES, 2011, p. 338). Por esse motivo, o estudo do esporte como fenômeno midiático não pode se limitar a uma mera análise dos seus discursos, já que os conteúdos também expressam elementos sociais verdadeiramente excepcionais de cada país.

A Copa do Mundo de Futebol da FIFA 2014 no Brasil entrou na ordem do dia da mídia e da sociedade brasileira, sendo organizada como megaevento. Esse grande acontecimento incrementa consideravelmente o tratamento midiático desse país sul-americano, como demonstra a criação de novos correspondentes da mídia mundial, até então não presentes.

Entretanto, hoje um jogo da Copa do Mundo é considerado uma mercadoria, pois se relaciona a um público degustador de futebol e que, direta ou indiretamente, paga, sustentando esse espetáculo mundial (DAMO, 2011). O núcleo da estrutura do esporte midiático se baseia na produção de espetáculos para o consumo de símbolos e rituais. (MORAGAS, 2010). Dessa forma, a realização da Copa no Brasil permitirá ao país alcançar ampla visibilidade mundial, já que eventos desse porte geram uma maior promoção de sua imagem no exterior (DALONSO; LOURENÇO, 2011). Esse evento representa uma grande oportunidade para o Brasil reforçar a sua imagem, propiciando seu crescimento econômico como país emergente. O PIB (Produto Interior Bruto) do Brasil é o mais alto da América Latina, e seus setores agrícola, industrial, de minérios e de serviços são abundantes e estão desenvolvidos. A eles temos que somar 0 incremento do turismo durante o período de preparação e competição, e sobre todo o período posterior ao acontecimento Copa do Mundo (COLLADO, 2012).

\section{MÍDIAS, IDENTIDADE E ESPORTE}

Fausto Neto (2002) diz que a sociedade brasileira, na sua multiplicidade cultural e étnica, tem seus modos de operar suas agendas peculiares sobre o esporte. Esses movimentos capitalizam os campos sociais na medida em que esses modos de sentir servem de referência para que diferentes campos ressimbolizem esses registros no âmbito de suas agendas. 0 mesmo autor destaca que o esporte, além de ser uma atividade cultural e lúdica, também é permeado por outras temáticas não necessariamente esportivas, mas que incidem sobre a maneira de o esporte funcionar. Desse modo, o esporte converteu-se em matéria política e comercial, enquanto sua capacidade educativa é reduzida a um simples elemento de manipulação e alienação (ALCOBA, 2009). Fausto Neto (2002, p. 13) conclui: "o esporte tem no lúdico e no simbólico, apenas uma de suas dimensões, pois ao lado dessas acorrem funções e dimensões outras que pertencem à 
natureza de outros interesses." Vicent e Hill (2013) destacam que um grande evento esportivo cria vínculos ideais, que nos permitem examinar diversas identidades culturais.

Ao promover a Copa do Mundo de Futebol, o governo brasileiro aproxima olhares globais que buscam assistir às competições e ver o que o país tem a expor. Ou seja, com essa exibição, a imagem que o Brasil consolidará será a que ficará diante do mundo (OLIVER, 2012). Todas essas ações respondem a um mesmo objetivo: uma cultura que se sabe e se sente observada pela audiência internacional de grandes dimensões, através dos meios de comunicação que irão cobrir a espetacularidade de um acontecimento singular (MORAGAS, 1992).

O Brasil, conquistando o primeiro campeonato mundial de seleções em 1958 e, logo em seguida, conquistando o bicampeonato, em 1962, fez desse esporte a materialização da representatividade nacional. No sentido de interpretar e ressignificar o esporte, acreditamos que, pelo fato de que nem todas as pessoas se identificam com um determinado tipo de esporte ou evento esportivo, as mídias procuram estabelecer relações regionais ou nacionais através do seu discurso. 0 esporte tornou-se importante nas sociedades modernas para a identificação de indivíduos com as comunidades a que pertencem, ou seja, para a formação e a manifestação de sentimentos coletivos e o equilíbrio grupal (DUNNING, 2003). Desse modo, a identidade nacional vê-se reforçada através da construção seletiva de versões idealizadas da realidade do país, apoiando-se exclusivamente nos sucessos do passado como parte da consciência nacional (VICENT; HILL, 2013). A mídia comunica-se com o seu receptor/consumidor através de processos identitários (formas de enquadramentos) estabelecidos pela sociedade/cultura em que ele está inserido, dentro dos mais diversos campos. E, embora o esporte, em sua essência, seja um exercício banal, trivial e efêmero, também expõe, de maneira pública, alguns dos relatos e das histórias que sustentam comunidades e identidades que dão sentido a uma sociedade, tanto local como global (BOYLE, 2006). O enquadramento da linguagem regional e de aspectos culturais locais na cobertura são "recheios" necessários para dar sentido ao resultado do campo esportivo na aldeia. Dessa forma, os enquadramentos operam fundamentalmente com o que se imagina ser o contexto do leitor, que se trata de elemento essencial para o estabelecimento da comunicação.

Cabe relacionar com este estudo a fala de Bourdieu (2004) em seu texto "A identidade e a representação: elementos para uma reflexão crítica sobre a ideia de região". Para o autor, o discurso regionalista é um discurso performativo, que tem em vista impor como legítima uma nova definição das fronteiras e dar a conhecer e fazer reconhecer a região assim delimitada. Como as categorias de parentesco, instituem uma realidade usando do poder de revelação e de construção exercido pela objetivação do discurso. Bourdieu ainda enfatiza que a objetivação do discurso não depende somente daquele que o detém, mas também do grau em que 0 discurso se anuncia ao seu grupo de identidade, isto é, no reconhecimento e na crença que Ihe concedem os membros desse grupo. Nesse particular, as mídias buscam, através de seu discurso, evocar questões identitárias, culturais, de representação, em sua cobertura. É um processo que implica para a mídia a escolha e a determinação dos referenciais socioculturais e geopolíticos básicos para interpretar a realidade sociopolítica (MORAGAS, 1992).

Os jornais investigados, Folha de S. Paulo e El Pais, são jornais tradicionais de seus respectivos países, apresentado características próprias. A Folha foi fundada por Olival Costa, Pedro Cunha e outros jornalistas em 19 de fevereiro de 1921 com o nome de Folha da Noite. 
operária. Em julho de 1925, foi lançado um matutino com o nome de Folha da Manhã (Manual da redação, 2011). O jornal declara-se abertamente como "um produto" sujeito às leis do mercado, que valoriza a modernização e o profissionalismo. A Folha declara fazer um jornalismo moderno, crítico, analítico, especializado, de serviço, plural e apartidário. Os critérios para a escolha das notícias seriam o ineditismo, a improbabilidade, 0 interesse, 0 apelo e a empatia (MANUAL..., 2011).

O Grupo Folha atualmente é um dos principais conglomerados de mídia do país. Controla o jornal de maior circulação e influência (Folha de $S$. Paulo), a maior empresa brasileira de conteúdo e serviços de internet (UOL), o site noticioso de jornal com mais audiência (Folha.com) e a maior gráfica comercial do Brasil (Plural), além de outros negócios. 0 grupo que emprega nove mil pessoas e gera cerca de sete mil empregos indiretos conta também com o Datafolha, um dos institutos de pesquisa mais respeitados do país, uma editora de livros (Publifolha), uma livraria virtual (Livraria da Folha), uma agência de notícias (Folhapress), um dos maiores e mais modernos parques gráficos da América Latina (CTG-F), a TransfoIha, dedicada à distribuição de produtos do Grupo Folha, uma gráfica dedicada a jornais e foIhetos para empresas, editoras e agências de publicidade (Folha Gráfica) e a SPDL, empresa de distribuição e logística estabelecida em associação com o jornal $O$ Estado de $S$. Paulo. O jornal EI País faz parte do grupo PRISA, considerado atualmente o maior grupo de comunicação da Espanha. Do ponto de vista editorial, "se define como uma mídia independente, nacional, de informação geral, com uma clara vocação global e especialmente latino-americana" (El PAÍS, 2014, p. 27). Precisamente, esse interesse internacional se traduz em uma edição global que é impressa e distribuída na América Latina. O jornal conta desde novembro de 2013 com uma edição digital exclusivamente em português para o Brasil, com uma redação própria em São Paulo.

Do ponto de vista ideológico, o El País é considerado desde seu início (1976) uma referência às tendências socialdemocratas próximas à centro-esquerda espanhola. Entretanto, nos últimos anos, sua linha editorial tomou posições mais próximas ao liberalismo, demonstrado por suas posturas críticas contra a nova esquerda na América Latina vinculada aos movimentos populistas, sendo especialmente crítico em determinados assuntos relativos a questões políticas e sociais (El PAÍS, 2014).

Quanto à informação esportiva, o El País se caracteriza tradicionalmente por oferecer um tratamento menos sensacionalista em comparação com a imprensa especializada espanhola (Marca, Sport, etc.). Porém, nos últimos anos a cobertura jornalista sobre a seleção nacional de futebol apresenta um tratamento mais triunfalista, favorecido não só pelas últimas conquistas esportivas (Eurocopa 2008, 2012 e Copa do Mundo 2010) como também pelos próprios interesses comerciais e publicitários que o grupo PRISA adquiriu. Neste sentido, o jornal começou a incluir anúncios da mídia radiofônica da cadeia SER, pertencente ao mesmo grupo que o El País, com um marcado tom de apoio à seleção espanhola de futebol.

\section{MÉTODO}

\subsection{0 corpus}

A presente pesquisa caracteriza-se como descritiva/quantitativa/qualitativa, tendo como corpus os jornais Folha de São Paulo e El País referente às edições de 27 de junho a 2 de julho 
de 2013, representando o dia em que foi definida a final da Copa das Confederações entre Brasil e Espanha e, dois dias após, o dia da final. O método escolhido para a realização desta pesquisa é a análise de conteúdo de Bardin (2011). Esse processo consiste em quantificar certos elementos que aparecem no texto, a fim de reconhecer a ocorrência predominante em relação a outros. Os dados trazem uma série de interpretações e conclusões relacionadas com as variáveis estudadas. Em termos de Krippendorff (1997, p. 28), a análise de conteúdo permite a realização de "inferências replicáveis e válidas que podem se aplicar ao seu conteúdo."

\subsection{As categorias de análise}

A partir das unidades de significados (os textos, as imagens, a publicidade, os editoriais, os painéis, as matérias, os títulos, a linha de apoio e outros canais), foram estabelecidas as seguintes categorias (as categorias foram criadas a partir do material empírico analisado, não sendo apriorísticas):

1. Esporte resultado: representa aspectos relativos à disputa do esporte em si, considerando aspectos técnicos, táticos e físicos.

2. Esporte economia: representa o esporte como negócio, discutindo investimentos, patrocinadores, licitações e despesas relativas ao futebol/Copa do Mundo e Copa das Confederações.

3. Esporte infraestrutura: apresenta aspectos relativos à criação, à restauração e ao aumento de aeroportos, estádios, vias, hotéis, como demanda de verba, financiamento, projetos de reforma ou de construção, etc. para a Copa das Confederações e a Copa do Mundo de Futebol.

4. Questões políticas e sociais: apresenta aspectos relativos à política e às manifestações sociais ocorridas no Brasil vinculados à Copa das Confederações e à Copa do Mundo de Futebol.

5. Publicidade: retrata as publicidades veiculadas nos jornais com motivação da Copa das Confederações ou da Copa do Mundo de Futebol e desmembra-se nos financiadores do evento esportivo e também dos apoiadores da Folha de São Paulo.

As técnicas qualitativas permitiram realizar uma análise textual e visual, sem esquecer o fundo contextual e as suas dimensões, que dão conta das estruturas do discurso em diferentes níveis de descrição. As dimensões contextuais relacionam-se com essas descrições estruturais com propriedades diferentes do contexto, como os processos cognitivos e as representações, ou os fatores socioculturais (DIJK, 1990). Os dados foram apresentados através da estatística descritiva, representados por percentuais e analisados qualitativamente conforme descrição abaixo.

\subsection{Apresentação dos dados e discussão}

Abaixo, apresentamos os gráficos referentes às categorias estabelecidas por cada jornal analisado, Folha de S. Paulo e El País. Cada unidade de significado foi chamada de inferência após a sua classificação nas categorias analíticas. 


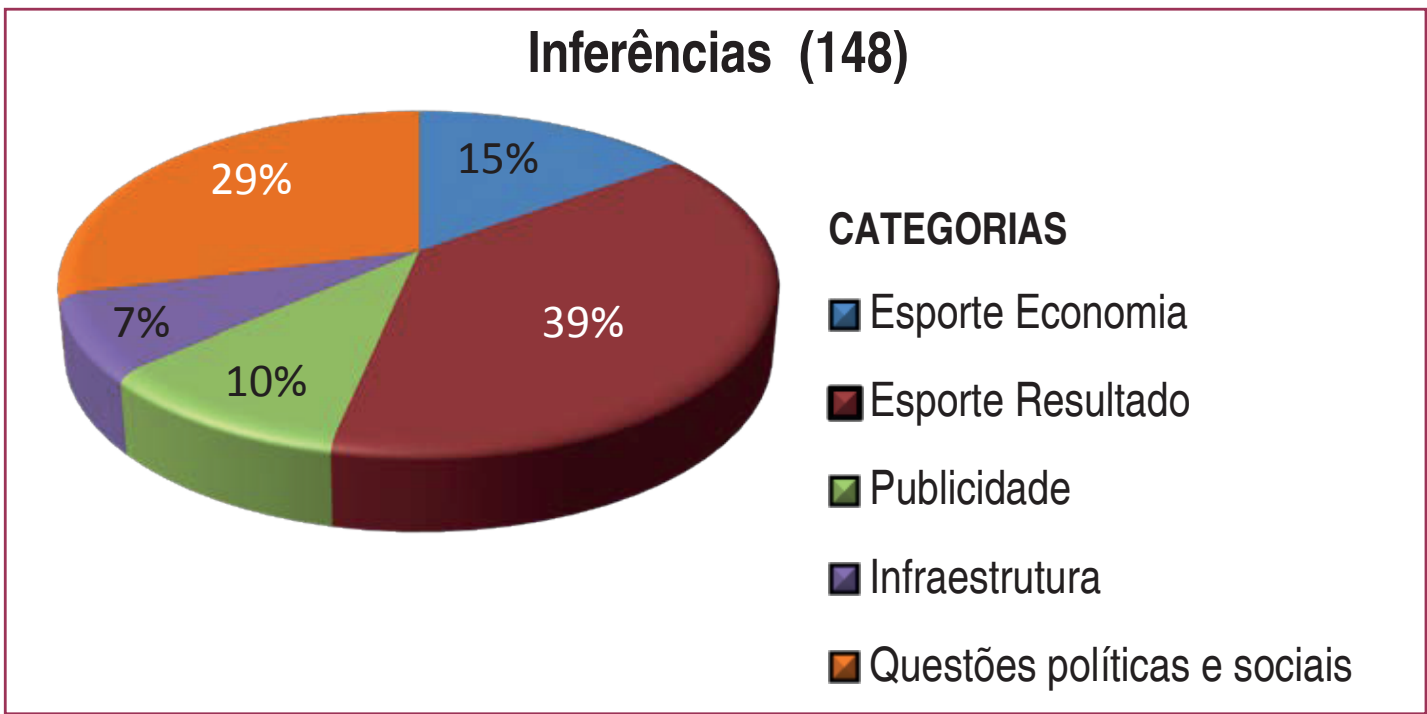

Fonte: Elaborado pelos autores

Figura 2 - El País

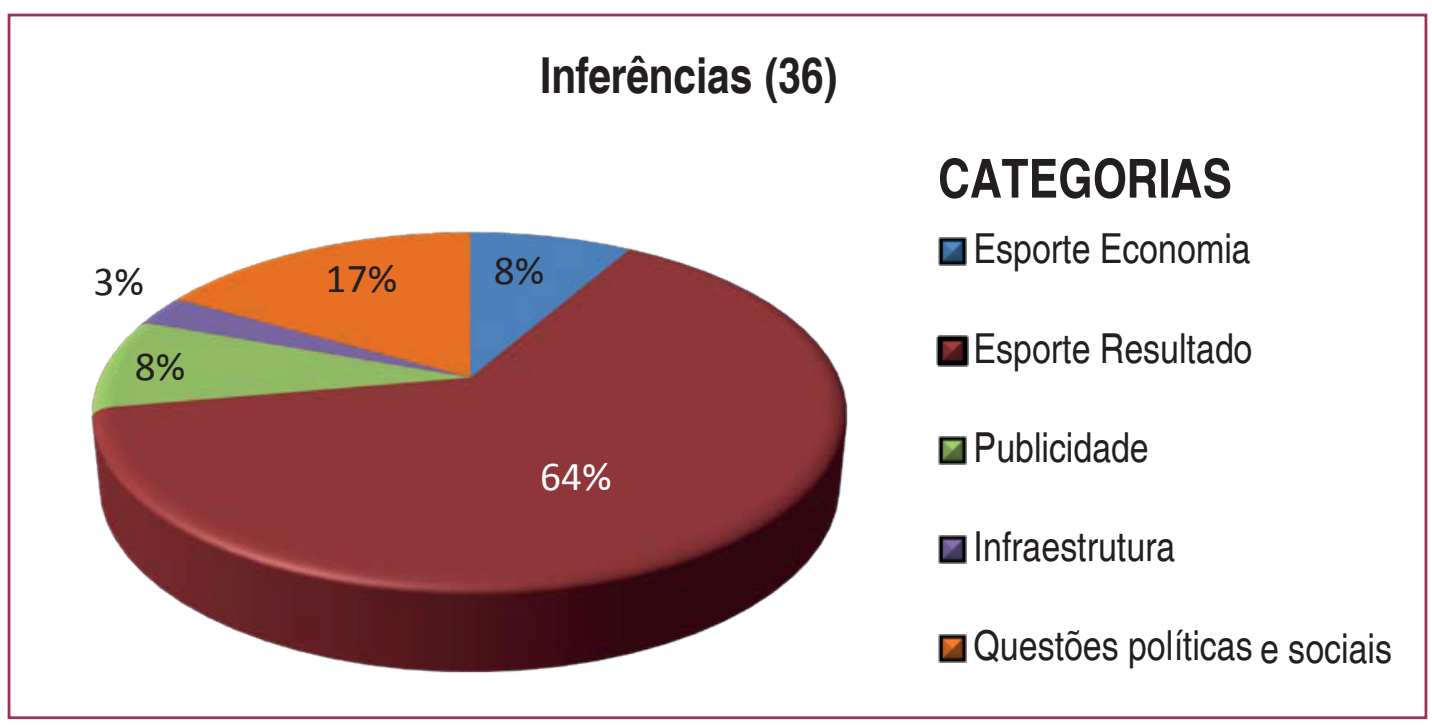

Fonte: Elaborado pelos autores

O primeiro gráfico acima representa o total de unidades de significados extraídas da Folha de S. Paulo (148), por categoria. Seguindo a lógica da construção da notícia, em que o fato preponderante no período de análise do recorte é a final da Copa das Confederações, a categoria Esporte Resultado configura-se com 39\% do total, seguida de Questões Políticas e Sociais, com 29\%, 15\% Esporte Economia, 10\% Publicidade e, por fim, 7\% Infraestrutura. Da mesma forma, o segundo gráfico representa as inferências extraídas do El País (36). Neste caso, chama a atenção que Esporte Resultado representa $63 \%$ do total, seguido pelas Questões Políticas e Sociais, com 17\%, e 8\% para Publicidade e Esporte Economia. A categoria Infraestrutura figura com apenas $3 \%$ do total.

No quadro a seguir, apresentamos as inferências por categoria e dia nos respectivos jornais. 
Figura 3 - Inferências por categoria/jornal/dia

\begin{tabular}{ccccccccc}
\hline & 27/06 & $\mathbf{2 8 / 0 6}$ & $\mathbf{2 9 / 0 6}$ & $\mathbf{3 0 / 0 6}$ & $\mathbf{0 1 / 0 7}$ & $\mathbf{0 2 / 0 7}$ & Total & \\
\hline Esporte & Folha de São Paulo & 12 & 10 & 7 & 13 & 13 & 2 & 57 \\
Resultado & El País & 5 & 4 & 3 & 5 & 5 & 1 & 23 \\
Esporte & Folha de São Paulo & 4 & 1 & 5 & 3 & 3 & 6 & 22 \\
Economia & El País & 1 & 1 & 0 & 1 & 0 & 0 & 3 \\
& Folha de São Paulo & 0 & 2 & 1 & 2 & 5 & 1 & 11 \\
Infraestrutura & El País & 0 & 0 & 1 & 0 & 0 & 0 & 1 \\
Questões & Folha de São Paulo & 6 & 3 & 13 & 4 & 7 & 10 & 33 \\
Políticas e & El País & 3 & 0 & 1 & 1 & 1 & 0 & 6 \\
Sociais & & & & & & & & \\
& Folha de São Paulo & 3 & 3 & 3 & 6 & 0 & 0 & 12 \\
Publicidade & El País & 1 & 1 & 0 & 1 & 0 & 0 & 3 \\
\hline Total & $(\mathbf{X})(\mathbf{X})$ & $(25)(10)$ & $(19)(6)$ & $(29)(5)$ & $(28)(8)$ & $(28)(6)$ & $(19)(1)$ & $(184)$ \\
\hline
\end{tabular}

Fonte: Elaborado pelos autores

Observamos, conforme a tabela acima, uma intensidade maior do Esporte Resultado em ambos os jornais, principalmente no dia da final da Copa das Confederações (30/06) e pós-final (1\%/07). As manifestações populares em época da Copa das Confederações também tiveram espaço nas coberturas, tendo inferências em todos os dias da análise. Em contraponto, - El País não apresenta nenhuma inferência da categoria Questões políticas e sociais nos dias 28 de junho e 2 de julho de 2014. A seguir, apresentamos aspectos relativos à construção da notícia nos respectivos jornais.

\subsection{A processualidade da construção da notícia}

\section{7 de Junho}

No dia 27 de junho, no jornal Folha de S. Paulo, obtivemos 25 inferências retratando a Copa das Confederações, oscilando entre capas, imagens, notas, editoriais e notícias. Há maior destaque no Caderno de Esportes, com 14 delas. A capa principal dá início à valorização da Seleção Brasileira, expressando-se com o título "Adiós, Uruguai", após ter saído vitoriosa por $2 \times 1$ contra o time.

Nesse dia, a categoria Esporte Resultado sobressaiu-se, discutindo assuntos de identificação da população com os jogadores, incentivando-os a buscar dentro de si o orgulho nacionalista e remir as manifestações ${ }^{1}$ contra a Copa e seus gastos, que estavam ocorrendo paralelamente aos jogos, pois a Seleção buscava o seu quarto título na competição e, com a sua vitória, gerou esperanças ao povo em decorrência dos milagres que o time realizou.

Para Muller et al (2013), a abordagem relativa à Copa das Confederações e à própria Copa do Mundo 2014 passaram, portanto, a partir das manifestações de junho, a serem pautadas de maneira diferente, visto que a opinião pública se mostrou bastante descontente com

1 Sobre as manifestações de junho de 2013: em relação às manifestações, no contexto geral, em 11 de junho, dias antes ao início da competição, um movimento organizado via rede social, intitulado Movimento Passe Livre (MPL), seguindo ao que já havia acontecido em Porto Alegre e no Rio de Janeiro, com aproximadamente 11 mil pessoas, deslocou-se à Avenida Paulista, para protestar contra o reajuste da tarifa do transporte público decretado pelo prefeito Fernando Haddad e pelo governador Geraldo Alckmin dias antes. Houve depredação de patrimônios públicos e privados. 
as exigências feitas pela FIFA, especialmente no que se refere aos estádios de futebol. Esse comportamento nos é revelado pela segunda posição ocupada pela categoria "questões políticas e sociais" na análise do recorte aqui proposto. Tal descontentamento se mostrou muito consistente nos protestos e nas manifestações, que se intensificaram durante a Copa das Confederações e que tomaram, inclusive, o entorno de diversos estádios de futebol, antes e depois da realização dos jogos do evento.

O discurso dos media é fruto da mediação social feita pela própria mídia. A representação social do campo esportivo em época de Copa do Mundo faz-se através das mídias, que, pela sua cobertura, representa e faz-se representar. Nesse sentido, a Folha busca a representação da vitória, alinhada com elementos da cultura local, que despertam o imaginário social acerca do resultado do campo esportivo (SANFELICE, 2007). Esse imaginário se configura como uma representação simbólica, como forma de dar significado a esse fazer do campo esportivo. Tratando-se da relação entre campos, Rodrigues (1997) destaca que o discurso midiático também desempenha um importante papel de reforço da legitimidade das outras instituições, ajudando a mantê-las presentes no imaginário social. Sendo assim, a Folha desloca o foco para composições visuais e discursivas que destacam os vínculos entre esporte (futebol) e identidade nacional; esse vínculo é positivado pelo sentimento festivo da vitória da seleção brasileira. Desse modo, minimiza-se [realiza o "apagamento"] a discussão sobre gastos públicos na Copa, pautada pelas manifestações sociais, mesmo sendo o tema das manifestações pauta de todas as edições no período analisado.

Nesse caso, se levarmos em conta apenas as cinco capas - através de suas imagens e suas manchetes -, identificamos que quatro destas oferecem à nossa percepção uma sensação² dual: de um lado, a do festejo, sendo o núcleo desse sentimento o futebol (a comemoração com o abraço da vitória), e, de outro lado, dividindo nossa atenção, temos a sensação da revolta; aqui, ganham força as imagens dos manifestos, dos atos de reação social aos problemas brasileiros. Essas imagens revelam o sentimento de luta cotidiana, do povo que luta, da reação massiva às mazelas políticas e sociais que nos envergonham. Em ambos os casos, seja através das imagens da comemoração da vitória, seja através das imagens da revolta nas ruas, são imagens que operam, paradoxalmente, o fortalecimento de traços identitários e, no domínio dos sentimentos que fazem vibrar, reforçam o sentimento de um novo tempo, de um despertar do ser brasileiro.

No mesmo dia, no jornal El País, tivemos nove inferências sobre a final da Copa das Confederações, sendo perceptível um discurso formal e técnico, que nos mobiliza mais em torno de avaliações racionais dos processos econômicos e sociais implicados na realização de um megaevento do que para os sentimentos (como os de identidade nacional) vinculados ao evento (mesmo que às vezes o fanatismo se propague, como exemplo desse fanatismo, temos a notícia na segunda página do jornal sobre incêndios e saques em Belo Horizonte durante 0 jogo entre Brasil e Uruguai). Nessa direção é que ganha força, no discurso do El País, a crítica ao Brasil sobre os gastos da Copa do Mundo, acentuando a questão através do título "Quantas Escolas valem um Maracanã?", com uma fotografia de duas crianças justificando sobre os protestos que ocorriam concomitantemente à competição. Aqui, o El País apresenta um discurso crítico em relação ao gasto público, destoando da Folha de São Paulo. O jornal ainda traz, em

2 Referimo-nos aqui ao uso de recursos visuais e discursivos que produzem nos leitores uma explosão de qualidades que afetam e mobilizam sensações correspondentes ao que Peirce denomina de "A primeiridade", ou seja, aquilo que aparece em tudo que estiver relacionado com qualidade, sentimento, originalidade. (SANTAELLA, 2002, p. 7). 
espaço na Capa, a classificação brasileira para a final, ressaltando que o Brasil cumpriu seu papel ("Brasil ya está en su gran final") e que o Maracanã e um clássico contra Itália na semifinal são mais que suficientes para motivar os jogadores. Da mesma forma, realça-se o valor da defesa da seleção espanhola, através da ampla entrevista de Sergio Ramos, em contraste com o comentário sobre a vulnerabilidade da defesa da equipe italiana. Também é interessante notar a presença naquele dia de uma mensagem publicitária de apoio correspondente à estação de rádio "Cadena SER ${ }^{3 "}$ " "la última barrera antes de la final".

\section{8 de Junho}

No dia 28 de junho, no jornal Folha de São Paulo, obtivemos 19 inferências sobre a final da Copa das Confederações, estando sua maioria no Caderno de Esportes. A capa do jornal conduz a classificação da seleção espanhola para a final, após derrotar a seleção italiana na disputa por pênaltis, a imagem do jogador Sergio Ramos novamente ganha destaque, assim como durante toda a Copa das Confederações, tendo em vista a importância do zagueiro/ lateral-direito para La Roja.

Assim, percebemos um número grande de inferências (10) sobre o desempenho da seleção brasileira, entrelaçando os objetivos já atingidos de Felipão e realizando uma projeção de uma possivvel final. Também ressaltamos que, das 19 inferências, apenas uma falava dos manifestos nos arredores do estádio. A capa traz uma imagem de um cidadão com uma camiseta amarela encarando o batalhão da polícia. $O$ texto não faz nenhuma associação com a questão esportiva, no entanto realiza o alinhamento de sentidos entre a Copa das Confederações e as manifestações sociais, através do apelo icônico da camisa amarela - cor canarinha é ícone da seleção brasileira - de um manifestante, que é um senhor maduro, e não um jovem rebelde; além disso, a legenda destaca que o enfrentamento se deu junto ao estádio Castelão, atrelando, portanto, ambos os eventos: "Homem a homem: manifestante encara tropa da polícia nos arredores do estádio Castelão, em Fortaleza, onde confronto acabou com sete feridos e 72 detidos. No Rio protesto teve passeata pacífica com o coro 'A luta apenas começou'.

No Jornal El País, no dia 28 de junho, somente seis inferências discutiam sobre 0 evento e faziam alusão à classificação da Espanha para a final da Copa das Confederações, destacando, como na Folha de S. Paulo, a imagem do zagueiro/lateral-direito Sergio Ramos na capa do jornal. $O$ tom das notícias segue sendo técnico e objetivo, porém, diferentemente das edições anteriores, o fato de a seleção espanhola ter se classificado para a final contra 0 Brasil reposiciona o evento, elevando-o a uma condição de episódio heroico: a imagem que representa esse reposicionamento é a da comemoração da seleção espanhola, em que vários jogadores aparecem abraçados; trata-se de uma imagem afinada à ideologia da unidade espanhola representada pela La Roja. A legenda da imagem - "La épica de España alcanza Maracaná. La Roja jugará la final contra Brasil tras derrotar a Italia em los penaltis" - reforça a importância de confrontar uma seleção com tamanha visibilidade em um dos principais palcos do futebol mundial, o Maracanã. Assim, evidencia-se o discurso da vitória com manchetes como: "España no tiene punto final", sendo reforçada anteriormente nas páginas de publicidade com o texto do anúncio Movistar (companhia telefônica): "Ánimo España que esta final sea histórica".

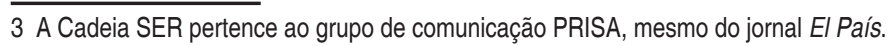


29 de junho

No dia 29 de junho, na Folha de S. Paulo, encontramos 28 inferências ainda sobre a final da Copa das Confederações, sua maioria estando unidas às Questões Políticas e Sociais e, por mais que já fosse certa a final entre Brasil e Espanha, termo utilizado pelos autores como "Final do Século", as notícias se posicionavam para o lado político. O restante das inferências fazem discussões sobre o legado, sobre a não exploração deste no país, retratando, de forma interessante, esse assunto, pois citam que, da mesma forma com que Neymar dribla os adversários em campo, o governo federal tem a mesma habilidade sobre as cobranças relacionadas à infraestrutura, etc. Outro assunto que merece destaque é a questão econômica, que surge através de uma coluna na qual se destaca a preocupação com cambistas e a guerra televisiva entre as redes Bandeirantes e Globo.

Segundo Ribeiro e Santos Junior (2013), surge no Brasil o sentido dos megaeventos tendo papel crucial na nova forma de padrão de governo nas cidades, fundado na governança empreendedora e no aprofundamento da mercantilização das cidades. Conforme os autores, esse fato nasce devido ao ciclo de estabilidade e prosperidade econômica apresentada pelo país, combinado com a existência de ativos urbanos passíveis de serem espoliados e integrados aos circuitos de valorização financeira internacionalizados, que contrariam, dessa forma, a lógica de regular as forças de mercado para torná-las compatíveis com a promoção do direito à cidade. Dentro do exposto, os autores apontam o fato de 0 Brasil estar vivenciando um momento em que 0 Estado intervém fortemente na economia, sob a hegemonia dos capitais financeiros internacional e nacional e sua lógica, em um padrão que poderia ser definido como keynesianismo neoliberal.

No mesmo dia, no jornal El País, tivemos cinco inferências sobre a final, e elas abrangiam vários temas. Assim, a notícia mais importante, que abre o caderno de esportes, "España se queja a la FIFA", descreve vários inconvenientes que a seleção espanhola encontrou em sua estada no Brasil. Porém, o que ganhou maior destaque tratava a respeito da possível "orgia" que os jogadores da Espanha tiveram com profissionais responsáveis pela estimulação erótica e sexual. Dessa maneira, percebemos que a cobertura do jornal se transforma em um relato pessoal que defende seus jogadores e ataca a imprensa brasileira por supostas notícias sensacionalistas da imprensa brasileira. Assim, insulta nossa organização, chamando-a de leviana e irresponsável, afirmando que essa é uma arma brasileira para desestabilizar os espanhóis: "Invento de uma Mídia sensacionalista, os jogadores espanhóis são inocentes". Outra questão destacada remete para o discurso de vitória do jornal espanhol, elogiando a abordagem tática de Del Bosque: "Hoy, La Roja ha despojado a Brasil del trono mundial del jogo bonito".

\section{0 de Junho}

No dia 30 de junho, no jornal Folha de $S$. Paulo, obtivemos 28 inferências sobre a grande final entre Brasil e Espanha, sendo que sua maioria aparece no Caderno de Esportes, retratando sobre a Categoria Esporte Resultado. Utiliza como referência principal o jogador Neymar, que aparece na capa do jornal e, ao lado, uma nota ressaltando: "Copa no Brasil é apoiada por 65\% dos brasileiros, diz Datafolha." Assim, por mais que a nossa seleção não fosse a favorita a ganhar e se esforçasse para superar a Espanha, o jornal traz relatos de Felipão, o qual deixa claro que o jogo "bonito" passaria e o que permaneceria seria o resultado, da mesma maneira com que poderíamos atrelar a frase do técnico à Copa 2014, prevendo que 
o agendamento repassasse através da vitória, absolvendo qualquer outro assunto. A Folha busca trazer, com veiculações de Neymar, a aceitação da Copa no Brasil.

A Folha de S. Paulo enquadrou o Brasil como "azarão" antes do jogo final, como podemos observar na capa do Caderno de Esportes do dia 30/06/13, dia da final.

Figura 4 - Capa do Caderno de Esportes do jornal Folha de S. Paulo no dia 30 de Junho de 2013

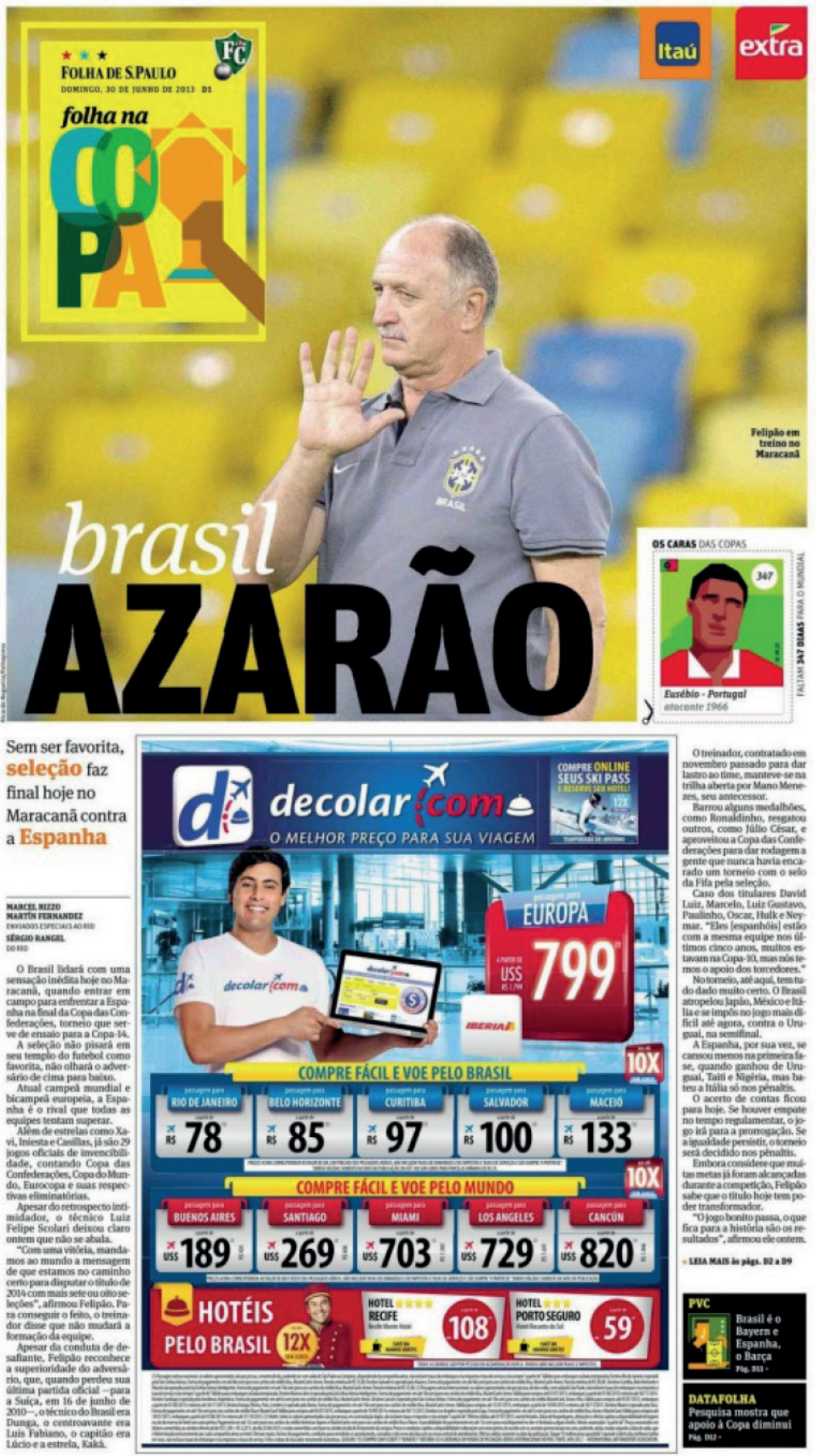

Fonte: Folha de S. Paulo, São Paulo, v. 93, n. 30769, p. D1, 30 jun. 2013.

Na mesma data, no jornal El País, evidenciamos sete inferências trazendo um agendamento à final. Fora do âmbito esportivo, devem-se destacar as duas referências a questões políticas e sociais em relação à perda de popularidade da presidente Dilma Rousseff com a 
onda de protestos que aconteceram em diferentes pontos do Brasil. O jornal resgata os cinco confrontos anteriores entre as duas seleções, como também uma entrevista com o técnico Vicente Del Bosque sobre Iker Casillas e uma notícia sobre o talento de Neymar, dedicando uma página completa sobre sua técnica e seu carisma: "El regate del filete de mariposa". Entretanto, o maior destaque é da única inferência publicitária do jornal que sobressalta a final que todos esperavam, a mística de enfrentar a seleção brasileira no Maracanã. El País intitula "A Espanha brasileira...", como mostrado na primeira página da seção de esportes do dia 30/06/2013, dia da final.

Figura 5 - Caderno de Esportes do jornal El País no dia 30 de Junho de 2013

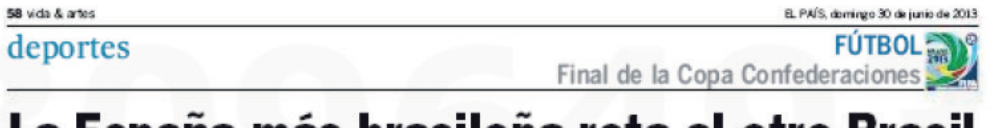
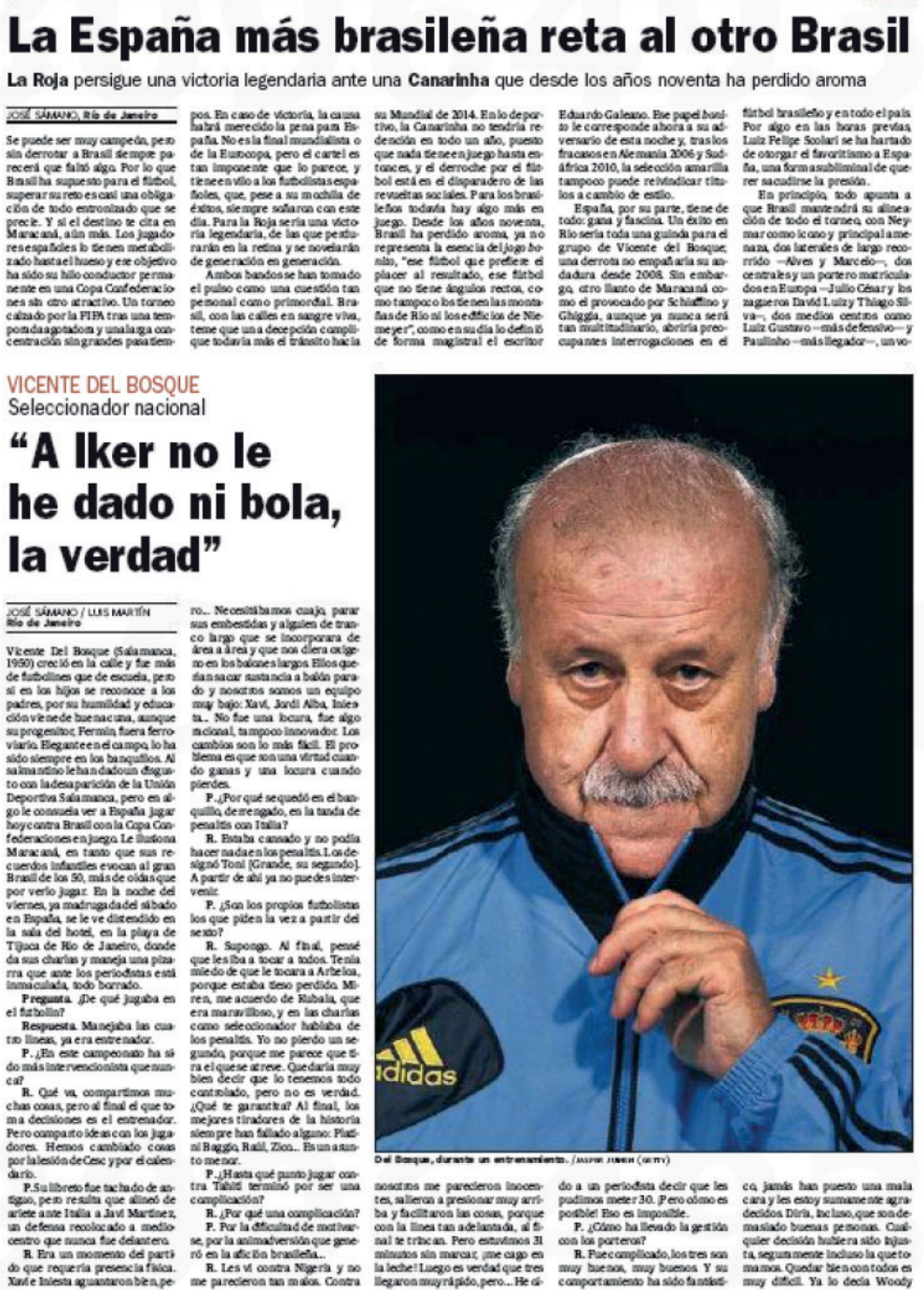

Fonte: El País, v. 38, n. 13150, p. 58, 30 jun. 2013. Caderno de Esportes do jornal.

$1^{\circ}$ de Julho

No dia $1^{0}$ de julho, o jornal Folha de S. Paulo apresentou 27 inferências sobre a final da Copa das Confederações, com o título da seleção canarinho, exibindo uma supremacia total das questões de Esporte Resultado com metade das notícias, porém 13 discutiam sobre o título da seleção, até mesmo as de publicidade, tal como o Supermercado Extra, que expõe "É Campeão! A Seleção da Família do Brasileiro". 
Após o resultado da final, o jornal, na capa do Caderno de Esportes, já realizado 0 "alinhamento" baseado no resultado do campo esportivo, colocou um foto de Neymar com a seguinte frase: "Imagina na Copa...", representando simbolicamente o resultado que poucos esperavam (nem mesmo a Folha, que se referia à seleção como "azarão" da Copa das Confederações).

Figura 6 - Capa do Caderno de Esportes do jornal da Folha de S. Paulo no dia 1ํ de Julho de 2013

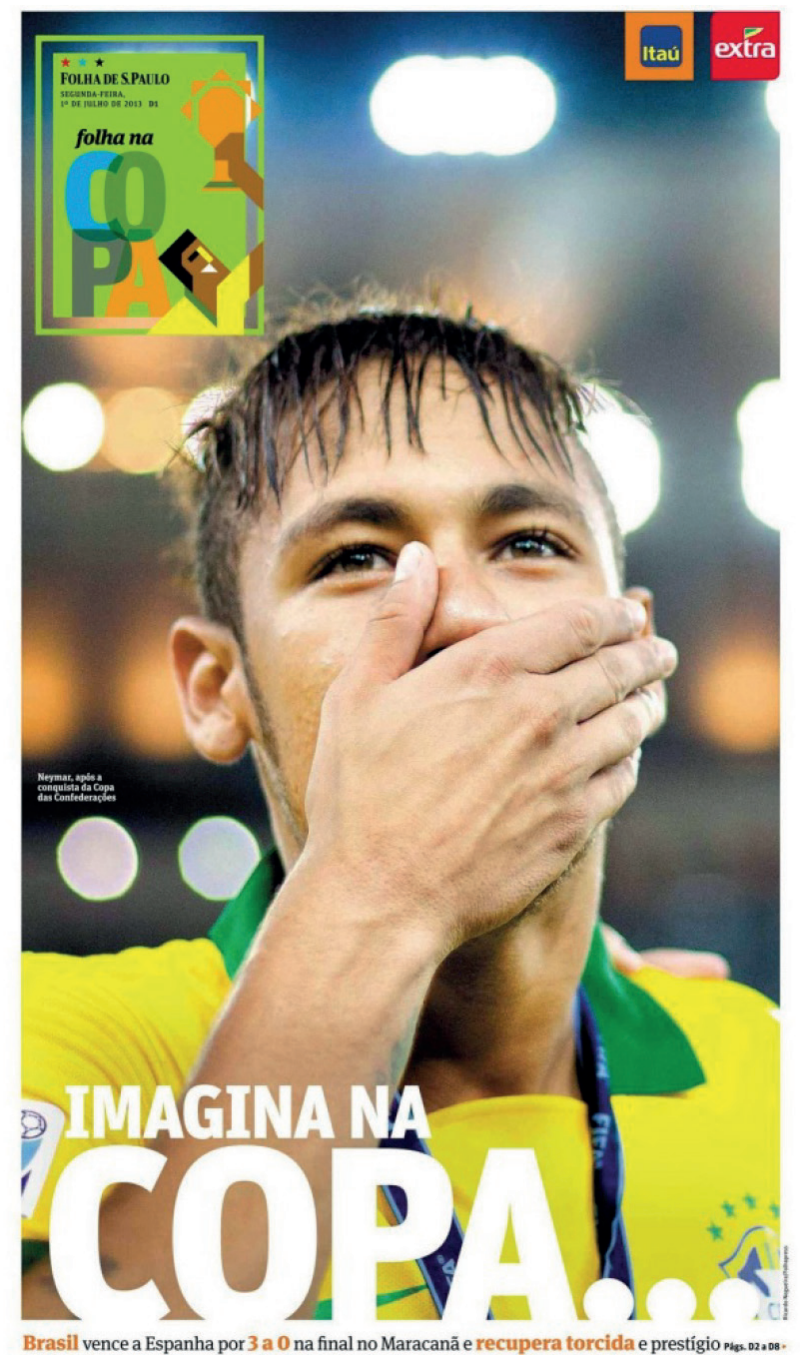

Fonte: Folha de S. Paulo, São Paulo, v. 93, n. 30770, p. D1, 1ำ jul. 2013. Caderno de Esportes.

O tema das notícias era o mesmo, falava-se de orgulho, brincava-se com a expressão "imagina na Copa”. Desse modo, o "despertar do gigante", ícone das manifestações de junho, era assimilado à lógica do evento esportivo: lembrava-se de que "O País pode dar certo", "O Campeão Voltou", na verdade o ufanismo brasileiro tomou conta do jornal e "banhou" todas as páginas, tudo voltava a ficar incrivelmente perfeito, com exceção de três notícias, que discorriam sobre as questões de infraestrutura, um levantamento do que foi o evento-teste, todavia um número inferior perto das outras 24 que enalteciam a seleção brasileira, de David Luiz, Fred, Júlio César, Neymar e o pai da nação, o Felipão.

Para fortalecer a confiança no alcance dos conteúdos noticiados, o jornal procura nos oferecer índices que demonstram que sua crença no "país que pode dar certo" tem bases concretas. Como exemplo, temos a legenda da imagem principal da capa do dia 1ํ de julho: " $A$ seleção voltou: contestado desde a Copa de 2010, Brasil retoma o bom futebol, dá olé, bate por 
3 a 0 a Espanha e leva a Copa das Confederações". Centrada na formulação "dá olé, bate por 3 x 0 a Espanha", temos a construção da verdade do fato: "dar olê", o número da vitória (3x0) e 0 fato de ser sobre a Espanha, objetivamente, a atual campeã mundial, fundam evidências que sustentam nossa condição de vitoriosos; são índices quantitativos/experienciais do ótimo futebol, que funcionam como base interpretativa para a ideia "de que pode dar certo".

Nesse dia, no jornal El País, tivemos seis inferências sobre a final da Copa das Confederações, na qual o Brasil saiu vitorioso e a Espanha, impotente. $O$ teor da notícia gira em torno de Neymar, que destrói com a seleção espanhola. Todavia, assim como no dia anterior, o jornal espanhol dá ênfase à importância de se jogar no Maracanã e contra a seleção brasileira e coloca esse fato acima da glória de se conquistar o título, a Copa das Confederações. A primeira página da seção de esportes começa com o título "El sueño de Maracaná fue una pesadilla", reconhecendo a inferioridade técnica e tática no jogo. Nas duas páginas seguintes, o periódico faz a crítica à defesa na derrota, através de dados estatísticos e gráficos. Após a final, o El País dedica boa parte de sua primeira página para o torneio. Em uma imagem, aparece Neymar comemorando um dos gols na frente de um deprimido Casillas com o título "La Roja se estrella ante Brasil". Em seguida, apresenta o jogador brasileiro de qualidade, capitalizando o Neymar como produto simbólico antes de sua chegada iminente à Liga Espanhola como jogador do Futbol Club Barcelona.

Figura 7 - Caderno de Esportes do jornal El País no dia $1^{\circ}$ de Julho de 2013
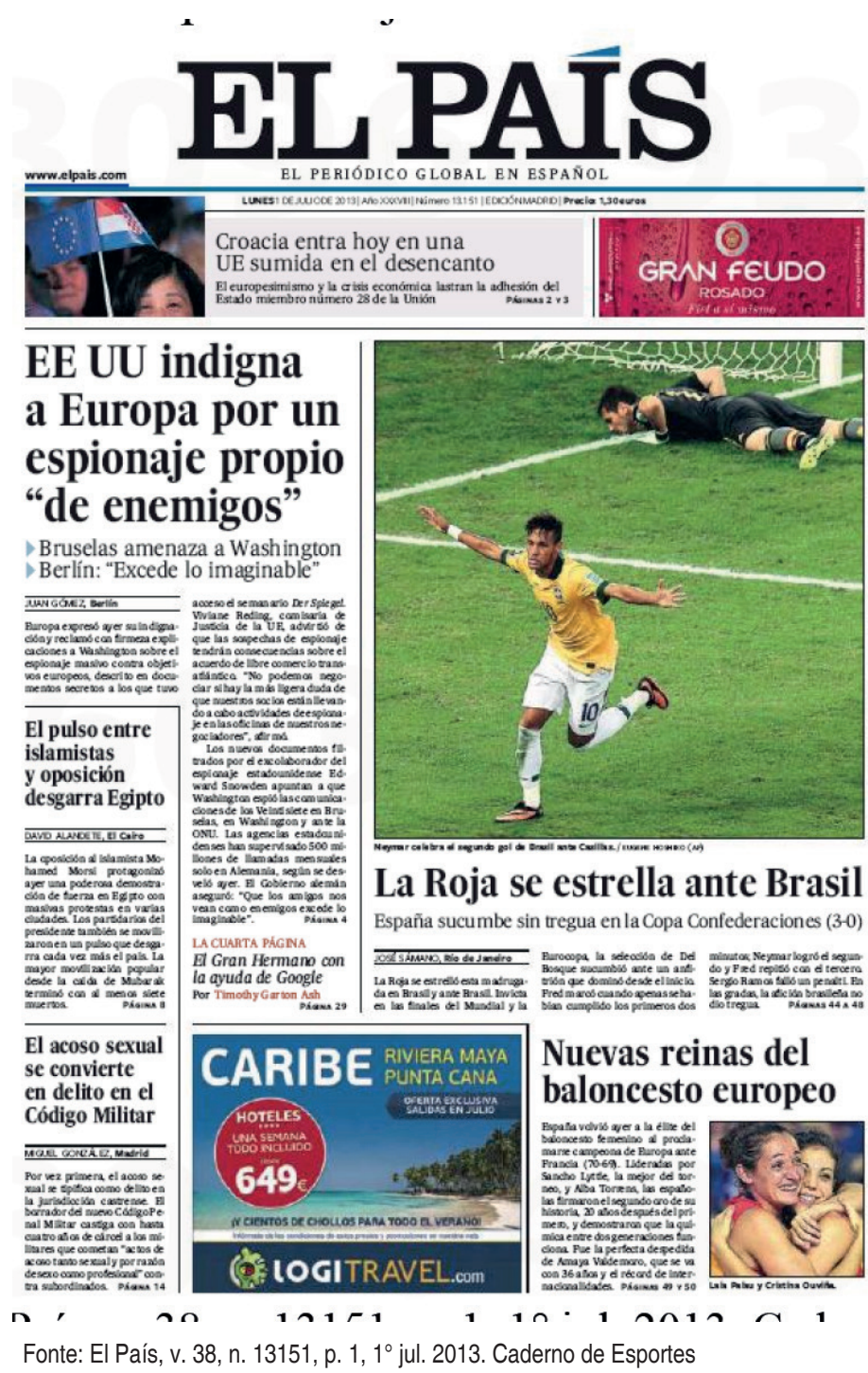
Significativamente, como frente à derrota espanhola se avaliza o papel de Neymar, tal como futuro atleta do FC Barcelona. Dentro da seção de esportes, é destacado como o jogador passa seu primeiro grande teste - "Neymar pasa su reválida" - acompanhado de uma foto de Neymar abraçando o seu novo companheiro de equipe, Xavi. Além disso, sua escolha como melhor jogador do torneio avaliza a compra pelo Barça, como demonstra o seu papel decisivo, conforme mostrado na Copa das Confederações.

\section{2 de Julho}

No dia 2 de julho, no jornal Folha de São Paulo, aparecem 19 inferências retratando sobre a Copa das Confederações, porém a vitória da seleção brasileira liga-se muito mais com a categoria Questões Políticas e Sociais, discutindo o possível reencontro da seleção com o torcedor, como também a conquista menos comemorada. $O$ agendamento do jornal, diferentemente do dia anterior, evidencia uma torcida mais crítica e, por mais que o futebol represente uma parte da nossa cultura, nossa nação está menos saciada somente com ele; é um Brasil querendo respeito. Assim, nosso país passa por sérios movimentos sociopolíticos vinculados ao futebol.

Por fim, é observado que, nesse dia, o jornal El País teve somente uma inferência sobre a Copa das Confederações, trazendo uma reflexão de como foi a final, como também fazendo críticas à seleção espanhola. Sob o título "La autocrítica serena de La Roja", examinam-se os erros táticos, principalmente da zona defensiva, associando a problemas de fadiga. Logo, o jornal valoriza o título brasileiro, mas já projeta um alerta sobre a forma de jogar da seleção brasileira, apontando o número excessivo de faltas e as faltas repetitivas nos jogadores-chave da seleção, tais como Andrés Iniesta. Realiza uma análise estatística de cada uma das 27 faltas cometidas durante a partida pela equipe brasileira em cada um dos jogadores espanhóis.

\section{CONSIDERAÇÕES FINAIS}

Em relação à cobertura da Folha de S. Paulo e do El País, podemos inferir que os jornais analisados realizaram coberturas díspares, principalmente pelo aspecto quantitativo, em que a Folha apresentou 148 inferências de análise contra apenas 36 do El País.

Por mais que entendamos que, pelo período do recorte (27 de junho a 2 de julho), a categoria Esporte Resultado prevaleceria em função do acontecimento da final da Copa das Confederações, é necessário perceber que, durante o período da Copa das Confederações, por diversas vezes as reportagens de cunho esportivo foram permeadas por questões sociais e políticas, dessa forma vinculando o assunto futebol às manifestações populares que eclodiram no país no mesmo período. Mesmo que à primeira vista - em função do número de reportagens voltadas ao esporte resultado - possamos afirmar que a Folha de $S$. Paulo tenha preferido rumar e apontar o foco principal do jornal à competição em si e que 0 agendamento de um tema implicaria necessário silenciamento do outro, a análise nos leva a reconhecer que houve contínuo esforço em noticiar ambos os fenômenos, criando condições de alinhamento entre um e outro, através da sua associação com o tema da identidade nacional, do ser brasileiro.

Nessa direção, a busca por interpretar as manifestações populares foi assimilada pelo jornal com base na mesma lógica com que ele representou o futebol, ou seja, como compo- 
nente de identidade nacional - expresso pela fórmula do voltar a vencer, do acordar. Assim, na ótica das mídias estudadas, os manifestantes, mesmo que parte desses sejam contra a Copa do Mundo, têm seus objetivos não diferenciados dos objetivos daqueles que defendem a Copa: a seleção e os manifestantes lutam por um Brasil vencedor.

Nas imagens da vitória da seleção na Copa das Confederações e nas imagens dos conflitos de rua em torno das manifestações, temos o emolduramento de indicativos de um projeto conservador que se traveste de novos tempos. É a retomada da vitória pelo futebol brasileiro frente ao atual campeão do mundo, a seleção espanhola, são as manifestações das classes médias por um Brasil moderno, são as condenações de políticos corruptos, enfim, são os governos que passam a repensar suas ações, em alguma medida, indicando que estão cedendo às demandas das ruas, são fatos esses cuja força histórica (objetiva) está assegurada pelas qualidades conservadoras que operam no fortalecimento de traços identitários e reforçam o sentimento de preservação, ordem, solidariedade e orgulho em torno desse sentimento de um Brasil maduro, capaz de receber e organizar um megaevento como a Copa. Vemos, então, que o esporte resultado - no âmbito do discurso da Folha de S. Paulo - transfere sua força simbólica para a compreensão da sociedade como um todo.

Quanto ao El País, com os dados obtidos a partir deste estudo, podemos verificar uma cobertura menos informativa. No entanto, é particularmente significativo que a cobertura em torno da Copa das Confederações permita que o jornal espanhol retrate aspectos novos do Brasil relacionados a questões políticas e sociais que não seriam tão visíveis, a não ser pela realização da Copa das Confederações.

Embora a categoria Questões Políticas e Sociais represente a segunda categoria mais evidenciada no estudo, atrás apenas da Esporte Resultado, em alguns casos, figura na primeira página da seção internacional do jornal com notícias e reportagens, especialmente, relacionadas com protestos de rua em cidades-sede do torneio de futebol.

Em relação à categoria mais tratada no El País, Esporte Resultado, ao longo dos dias analisados, evidencia-se um discurso especialmente vitorioso da seleção espanhola, diversificado em reportagens e entrevistas entre seus principais líderes, como Sergio Ramos, Iker Casillas, o próprio treinador Vicente Del Bosque. Nessa mesma direção, veicula-se também a publicidade, com suas mensagens de apoio dos patrocinadores da seleção espanhola (Movistar) ou dos meios de comunicação envolvidos na cobertura do torneio (Cadena SER radio).

As imagens e os outros elementos gráficos são muito ilustrativos, tanto relativamente à cobertura da Copa das Confederações como às manifestações sociais ocorridas no Brasil. Além disso, o jornal veiculou inúmeros dados estatísticos que acompanharam grande parte dos assuntos esportivos abordados, especialmente, relacionados com questões táticas do jogo.

Finalmente, observamos que o jornal espanhol, apesar da derrota da Espanha no torneio, realizou uma análise ponderada dos elementos a serem melhorados para a Copa do Mundo de 2014. Em contraste, destaca-se o tratamento informativo dado à figura de Neymar como eclosão e apresentação de uma nova figura e ícone publicitário na Liga Espanhola. Em suma, na categoria Esporte resultado, prevalece o discurso do El País com uma abordagem claramente de apoio e identificada com "La Roja", confiando que os erros serão corrigidos, a fim de defender o seu título na Copa do Mundo de 2014. 


\section{REFERÊNCIAS}

ALCOBA, Antonio. ¿Quo vadis deporte? Del fracaso olímpico al triunfo de política y capitalismo deportivo. Esteban Sanz, Madrid, 2009.

AÑÓ, Vicente. La organización de grandes eventos deportivos. Arbor Revista CSIC, Madrid, p. 265$287,2000$.

BARDIN, Laurence. Análise de conteúdo. São Paulo: Edições 70, 2011.

BOURDIEU, Pierre. 0 poder simbólico. 7. ed. Tradução de Fernando Tomaz. Rio de Janeiro: Bertrand Brasil, 2004.

BOYLE, Raymond. Sports Journalism. London: Sage, 2006.

COLLADO, Juan José. Impacto socioeconómico de los grandes eventos: el caso de Brasil. Barcelona: Universitat Politècnica de Catalunya, 2012.

DALONSO, Yoná da Silva; LOURENÇO, Júlia Maria Brandão Barbosa. O Brasil e a Copa Mundo Fifa 2014: um olhar além dos holofotes Brazil and the Fifa World Cup 2014: a look beyond the spotlight. book of proceedings. [s.I.]: Algarve 2011. v. 1 - International Conference On Tourism \& Management Studies, p. 518-528.

DAMO, Arlei Sander. Produção e consumo de megaeventos esportivos - apontamentos em perspectiva antropológica. Comunicação, Mídia e Consumo, São Paulo, v. 8, n. 21, p. 67-92, mar. 2011.

DIJK, Teuan Adrianus Van. La noticia como discurso: comprensión, estructura y producción de la información. Barcelona: Paidós, 1990.

DUNNING, Eric. El fenómeno desportivo: estúdios sociológicos en torno al deporte, la violencia y la civilización. Barcelona: Paidotribo, 2003.

El PAÍS. Libro de estilo. Madrid: Santillana Ediciones, 2014.

FAUSTO NETO, Antônio. O agendamento do esporte: uma breve revisão teórica e conceitual. Revista de Comunicação Verso \& Reverso, São Leopoldo, v. 16, n. 34, jan.jun. 2002.

HALL, Stuart et. al. A produção social das notícias: O 'Mugging' nos Media”. In: TRAQUINA, Nelson. (Org.). Jornalismo: questões, teorias e "estórias". Lisboa: Vega, 1999.

KRIPPENDORFF, Klaus. Metodología del análisis de contenido: teoría y práctica. Barcelona: Paidós, 1997.

MANUAL da Redação da Folha de São Paulo. São Paulo: Publifolha, 2011.

MELO, Victor Andrade de. Futebol: que história é essa?! In: CARRANO, Paulo Cesar R. Futebol: paixão e política. Rio de Janeiro: DP\&A, 2000.

MEZZAROBA, Cristiano; PIRES, Giovani de Lorenzi. Os jogos pan-americanos rio/2007 e o agendamento midiático-esportivo: um estudo de recepção com escolares. Revista Brasileira de Ciências do Esporte, Florianópolis, v. 33, n. 2, p. 337-355, abr.jjun. 2011.

MORAGAS, Miguel de. Comunicación y deporte en la era digital. [artículo en línea]. Barcelona: Centre d'Estudis Olímpics - UAB, 2010.

MORAGAS, Miguel de. Los juegos de la comunicación. Revista Telos, n. 30, jun./ago. 1992.

MÜLLER, Ivan Daniel et al. Manifestos sociais e copa das confederações na cobertura da Folha de São Paulo. Revista Motrivivência, v. 25, n. 41, dez. 2013.

OLIVER, lata. Megaeventos esportivos e relações internacionais como estratégia de atração turística. Observatório de Inovação do Turismo, Rio de Janeiro, v. 7, n. 1, abr. 2012. 
VICENT, John; HILL, John S. Media coverage of international sport. In: PEDERSEN, Paul M. Routledge handbook of sport communication. Abingdon: Routledge, 2013.

RIBEIRO, L. C. Q.; SANTOS JUNIOR, O. A. Governança empreendedorista e megaeventos esportivos: reflexões em torno da experiência brasileira. Revista 0 social em questão, Rio de Janeiro, v. 16, n. 29, 2013.

RODRIGUES, Adriano Duarte. Estratégias da comunicação. Lisboa: Editorial Presença, 1997.

SANFELICE, Gustavo Roese. Campo midiático e campo esportivo: suas relações e construções simbólicas. Revista Brasileira de Ciências do Esporte, Campinas, v. 31, n. 2, p. 137-153, 2010.

SANFELICE, Gustavo Roese. Os enquadramentos dos Jornais Zero Hora e Folha de São Paulo na cobertura de Daiane dos Santos nos Jogos Olímpicos de Atenas/2004: a midiatização do resultado esportivo. 2007. 200 f. Tese (Doutorado em Ciências da Comunicação) - Universidade Vale do Rio dos Sinos, São Leopoldo, 2007.

SANTAELLA, Lucia. Semiótica aplicada. São Paulo: Pioneira Thomson Learning, 2002.

TAFFAREL, Celi Neuza Zulke; SANTOS JUNIOR, Cláudio de Lira; SILVA, Wellington Araújo. Megaeventos esportivos: determinações da economia política, implicações didático-pedagógicas e rumos da formação humana nas aulas de Educação Física. Em Aberto, Brasília, v. 26, n. 89, p. 5766, jan.jun. 2013. 
Endereço para correspondência:

Gustavo Roese Sanfelice

Rua Carlos Gomes, 231, apto 1002.

Vila Rosa, Novo Hamburgo/RS. CEP: 93315-040.

Financiamento: Fundação de Amparo a Pesquisa do Rio Grande do Sul (FAPERGS) 